\title{
A Bibliometric Analysis of Reverse Osmosis: How Influential Can It Be?
}

\author{
Syafiqah Hanis Mohd Fauzi*, Norazaliza Mohd Jamil \\ Centre for Mathematical Sciences, Universiti Malaysia Pahang, Lebuhraya Tun Razak, 26300 Gambang, Kuantan, Pahang, Malaysia
}

Received January 28, 2021; Revised April 21, 2021; Accepted June 5, 2021

\section{Cite This Paper in the following Citation Styles}

(a): [1] Syafiqah Hanis Mohd Fauzi, Norazaliza Mohd Jamil , "A Bibliometric Analysis of Reverse Osmosis: How Influential Can It Be?," Environment and Ecology Research, Vol. 9, No. 3, pp. 134 - 143, 2021. DOI: 10.13189/eer.2021.090305.

(b): Syafiqah Hanis Mohd Fauzi, Norazaliza Mohd Jamil (2021). A Bibliometric Analysis of Reverse Osmosis: How Influential Can It Be?. Environment and Ecology Research, 9(3), 134 - 143. DOI: 10.13189/eer.2021.090305.

Copyright $\mathrm{C} 2021$ by authors, all rights reserved. Authors agree that this article remains permanently open access under the terms of the Creative Commons Attribution License 4.0 International License

\begin{abstract}
Reverse osmosis is a treatment process to produce highly purified water in wastewater management. However, the depth study on exploring and visualization of the publication in this area has not been made in detail. Hence, this study is designed to assess the worldwide research trends of the reverse osmosis field in terms of publication output, keywords, journals, countries, institutions, collaborations, research areas, authors, document types, and languages. This study aims to analyze the distribution patterns of reverse osmosis journal articles, the terminology, and the research topics. A bibliometric analysis was conducted on 6,939 research articles obtained from the Web of Science (WOS) database that were published from 1970 to 2019. The bibliometric map and network were generated using VOSviewer software. Results have shown that the most related keywords are desalination and nanofiltration. The most preferred journal with 40,314 total citations was published by Elsevier. Researchers from the United States contributed the most global publications. The most productive academic institution was the National University of Singapore among 25 leading countries. The reverse osmosis topic is mostly used in Engineering and Water Resources area. The researchers from South Korea were the most productive authors in this area. The findings of this study will enable interested researchers to understand the performance of reverse osmosis research worldwide and provide recommendations for further research.
\end{abstract}

Keywords Reverse Osmosis, Bibliometric,
VOSviewer

\section{Introduction}

Over the past 40 years, reverse osmosis membrane technology has grown to $44 \%$ of the world's desalination capacity and $80 \%$ of the world's total number of desalination plants. Reverse osmosis membranes are now the leading technology for modern desalination plants. They are applied with specialized pre-treatment and membrane device design to several saltwater resources [1]. It is well known that dissolute compounds can be isolated from their solvents by the process known as reverse osmosis [2]. Besides, according to Gambier and Badreddin (2009) [3], the plant-based membrane of reverse osmosis has become mainstream technology in several areas, such as eliminating alcohol and taint in the winery and medical applications, in semiconductor processing, in drinking and cooking for domestic purposes.

Although reverse osmosis technology has become increasingly involved, very few studies have concentrated on evaluating and analyzing scientific publications worldwide. In the previous work of Tanaka and Ho (2011) [4] about global trends of desalination for the period 1991 to 2008 , reverse osmosis was part of the discussion. They claimed that more research was recorded in earlier years and recently on marine desalination, incredibly on reverse osmosis. Many researchers focused on scale control on seawater distillery, acetic acid distillation, water distillation, solar distillation, and others during the 1950s. However, most of the research focused only on 
desalination instead of focusing on the method of desalination, such as reverse osmosis.

Despite the rapidly growing role of reverse osmosis in the $21^{\text {st }}$ century, few attempts have been made to collect systematic data on the reverse osmosis process research. The use of the Science Citation Index (SCI) as a recovery mechanism has rarely been questioned. Braun et al. (2000) [5] stated that the most recognized and used database for the study of scientific publications is the SCI from the WoS databases.

The Institute for Scientific Information (ISI) began gathering referencing and other literary effect data in 1945 onwards. The information was made available electronically in 1979. The Science Citation Index Expanded is the new journal citation and database accessible on the internet [6]. Moreover, the ISI, SCI, and WoS databases are the most widely used source databases for a detailed evaluation of scientific achievement in all fields of research [7].

In a previous work by Li and Wang (2010) [8], one of the most successful methods for collecting fresh water from ocean and other water sources is reverse osmosis desalination. During reverse osmosis desalination processes, the membrane properties have a direct impact on water quality and energy costs. Recently, major research efforts were made to create a high-performance reverse osmosis (RO) membrane. Other than that, Tanaka and Ho (2011) [4] conducted a study on global trends and performances of desalination research. This study aims to evaluate the global scientific performance of desalination research to assess the properties of research trends and performances.

In this paper, this study aims to analyze the reputation and trends of reverse osmosis research from 1970 to 2019 to help other researchers understand the overview of reverse osmosis research worldwide and predict the dynamic directions of the research. The objectives are as follows:

i. To analyze the distribution patterns of reverse osmosis journal articles.

ii. To investigate the contribution of productive authors, the leading countries, the most productive academic institutions, and the research areas.

iii. To focus on the terminology and the research topics.

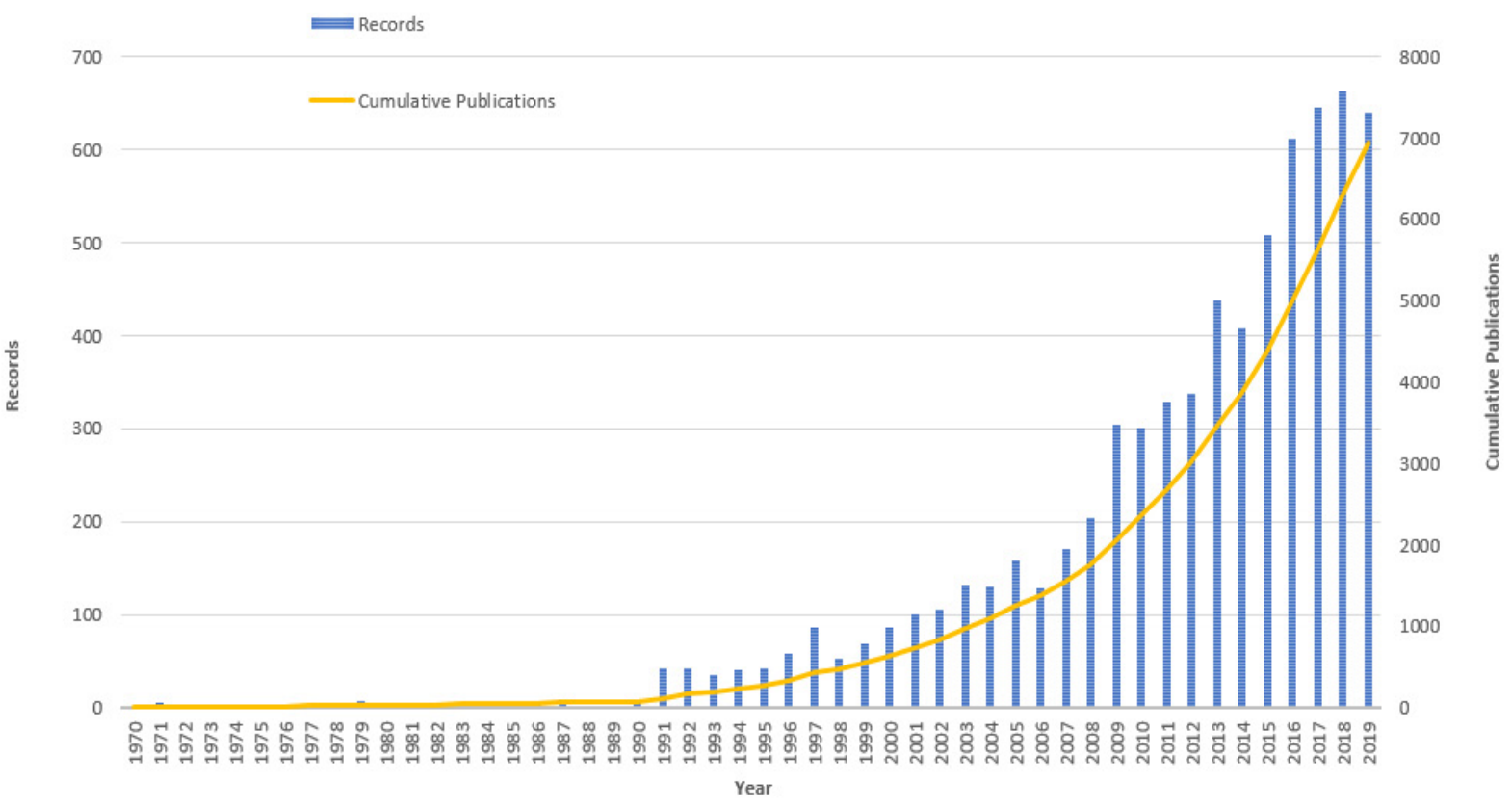

Figure 1. The records and cumulative publications of research articles on reverse osmosis in Web of Science from 1970 until 2019 


\section{Methodology}

A bibliometric analysis paper is distinct from a review paper, aiming mainly to examine the recent trends, challenges, and future directions for a particular subject [9]. This bibliometric analysis was carried out using the built-in tool of Web of Science and VOSviewer software.

\subsection{Data Source and Search Strategy}

The primary sources for the bibliometric data were by Thomson Reuter databases, which are the Science Citation Index, the Social Citation Index, and the Arts and Humanities Citation Index, now regrouped under the WoS [10]. "Reverse osmosis process" was used as the search phrase to search the topic in Web of Science. The results were further refined to include only articles or proceeding papers. The results showed that 7,035 accurate records were obtained from the Web of Science. This research has a limitation for the year of publication, and it is from the oldest publication, 1970, to the more recent, 2019. The search parameter used for the search was: TOPIC: (reverse osmosis process) AND YEAR PUBLISHED: (1970-2019) Refined by DOCUMENT TYPES: (ARTICLE OR PROCEEDINGS PAPER) AND DOCUMENT TYPES: (ARTICLE OR PROCEEDINGS PAPER) Timespan: All years. Indexes: SCI-EXPANDED, SSCI, A\&HCI, CPCI-S, CPCI-SSH, BKCI-S, BKCI-SSH, ESCI. As a result, there were 6,939 documents shown. Also, most document types were articles.

Based on the year, source, author, affiliation, country, research area, document types, languages, and the central topic's search, the results were evaluated. For ranking, bibliometric measures such as total publications, top institutions, leading authors, and h-index were used.

\subsection{Bibliometric Maps}

VOSviewer allocates research papers in related subjects, themes, or fields in clusters [11]. The 6,939 articles' data that contained all the records and cited references were exported to text files, and after that, the text files were exported to VOSviewer. The VOSviewer (Visualization of Similarities) is a software tool to create and display bibliometric maps. Also, the VOSviewer was applied to analyze and visualize the relationship among some objects. There are some virtual objects in this study, including country, author keyword, and leading author. There may be a link or relationship between two objects or any pair of objects. Every relationship has a value, which is a positive numerical value. The higher the value, the stronger the relationship between them [9].

\section{Results and Discussion}

\subsection{Annual Publications}

The total of research articles on reverse osmosis that had been published is 6,939 for 49 years. The records of articles and cumulative publications for the years 1970 until 2019 are shown in Fig.1. The figure shows that the number of articles increased rapidly from 1 to 6,939 and the increase started in the year 1991. The significant interest in reverse osmosis research has been proposed since 1990. Since then, annual publications have gradually risen, leading to a rapid rise in overall accumulated publications. The number of publications reached a peak (663 articles) in 2018, showing a gradual increase from 1991 until 2002 to reach 100 records. Despite that, after 2003 onwards, the increase in the number of publications was 200 every six years. In that case, the annual publication will maintain to increase.

\subsection{Author Keyword}

The author's keywords are an overview of the theme of an article that specifies a detailed information [12]. As the author's keyword analysis provides researchers with sufficient information on research patterns, it has proved extremely valuable in tracking the growth of research topics [13]. In the present study, the author keywords related to reverse osmosis are 10,464 in total. The minimum number of occurrences of keywords was set to five, meeting the threshold of 711 keywords for the mapping in VOSviewer.

The most frequently searched keywords with 1,645 co-occurrences and 4,020 links to other keywords are shown in Fig. 2. We also found the use of general terms, namely 'desalination' (5,671 occurrences, 1,769 links), 'nanofiltration' (604 occurrences, 1,490 links), 'forward osmosis' (412 occurrences, 1,060 links), and 'ultrafiltration' (234 occurrences, 922 links). There were also other conceptual keywords that co-occurred, such as 'fouling', 'membrane', 'water treatment', 'water reuse' and many more. Moreover, we observed that a few of attributes-substrate or combination keywords were used for the term of reverse osmosis. These included 'reverse osmosis membrane' (56 occurrences), 'reverse osmosis concentrate' (48 occurrences), 'seawater reverse osmosis' (36 occurrences), 'reverse osmosis desalination' (19 occurrences), 'reverse osmosis electrodialysis' (17 occurrences), and reverse osmosis brine' (5 occurrences).

'Desalination' and 'nanofiltration' were the most frequently used keywords. Desalination is a process of removal of salts and minerals from a substance to produce fresh water. RO is also best known for its application in desalination. Furthermore, nanofiltration (NF) is a membrane filtration method that is most used for water that has low total dissolved solids and removal of disinfection. In the previous work of Ahmad et al. (2006) [14], in areas where potable water demand has overwhelmed natural supply, reverse osmosis is most significant because it can reject all the solutes that ultrafiltration does not. In that case, from the observation, reverse osmosis and nanofiltration seemed to complement each other; hence many keywords co-occurred. Besides, according to Yang et al. (2018) [15], 
$\mathrm{RO}$, electrodialysis, and NF are all a good example of membrane technology, and observation in desalination research from 1997 to 2012 has proven the dominant position for membrane technology.

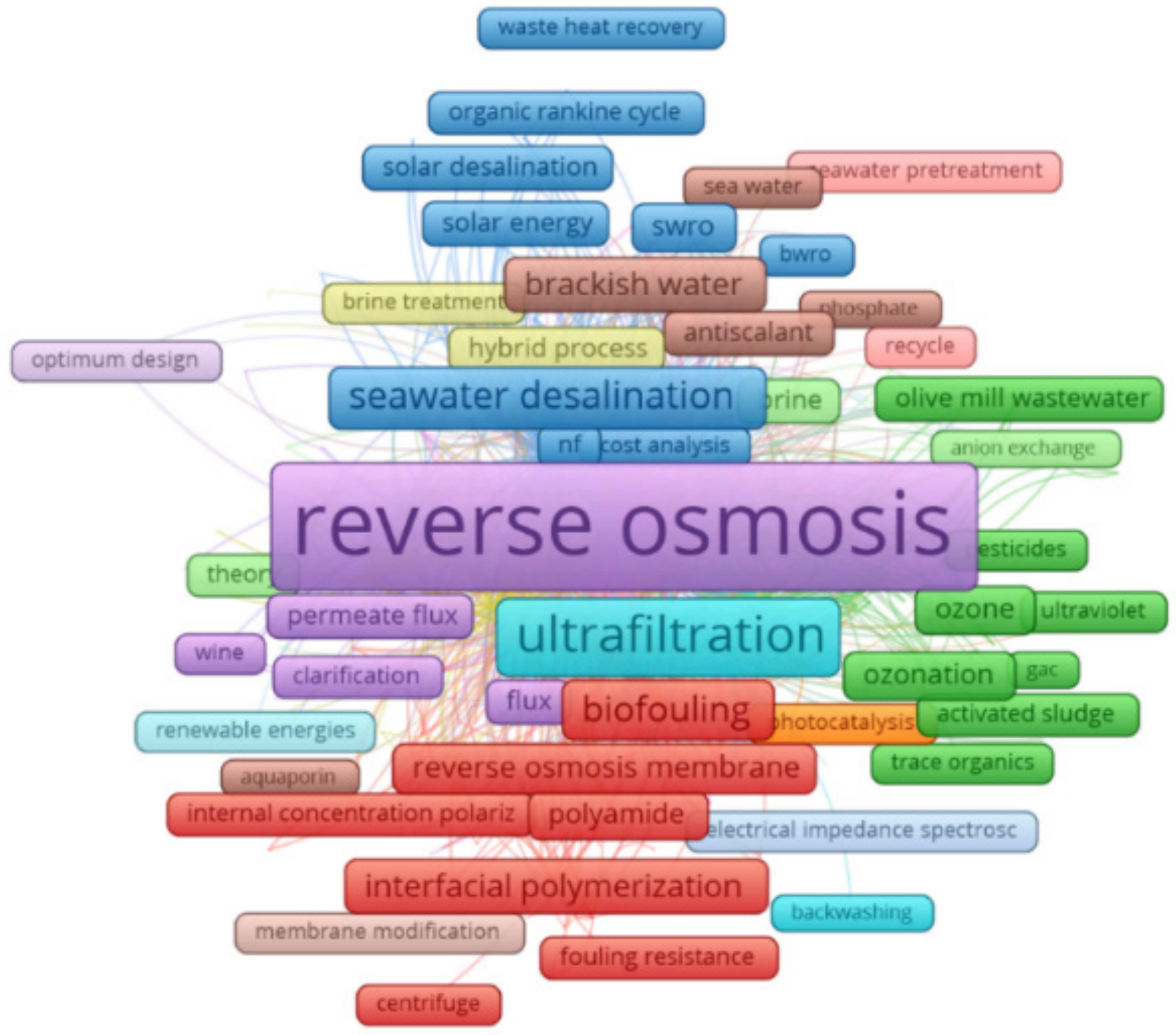

Figure 2. A screenshot of the bibliometric map created based on co-occurrence of author keywords with network visualization mode. The minimum number of documents of a country is set to five.

Table 1. The top 10 most productive journal on reverse osmosis research with total citations and journal impact factor trend in 2018.

\begin{tabular}{|c|c|c|c|c|c|c|}
\hline No & Journal & Publisher & Records & Percentage & $\begin{array}{c}\text { Total } \\
\text { Citations }\end{array}$ & $\begin{array}{c}\text { Journal Impact } \\
\text { Factor Trend 2018 }\end{array}$ \\
\hline 1 & Desalination (Q1) & Elsevier & 1,249 & $18.002 \%$ & 40,314 & 6.035 \\
\hline 2 & Journal of Membrane Science (Q1) & Elsevier & 714 & $10.291 \%$ & 36,696 & 7.015 \\
\hline 3 & $\begin{array}{c}\text { Desalination and Water Treatment } \\
(\mathrm{Q} 3)\end{array}$ & $\begin{array}{c}\text { Desalination } \\
\text { Publications }\end{array}$ & 695 & $10.017 \%$ & 4,604 & 1.234 \\
\hline 4 & $\begin{array}{c}\text { Separation and Purification } \\
\text { Technology (Q1) }\end{array}$ & Elsevier & 200 & $2.883 \%$ & 4,939 & 5.107 \\
\hline 5 & Water Research (Q1) & $\begin{array}{c}\text { Pergamon-Elsevier } \\
\text { Science Ltd }\end{array}$ & 189 & $2.724 \%$ & 9,653 & 7.913 \\
\hline 6 & $\begin{array}{c}\text { Environmental Science Technology } \\
\text { (Q1) }\end{array}$ & $\begin{array}{c}\text { American Chemical } \\
\text { Society }\end{array}$ & 130 & $1.874 \%$ & 7,967 & 7.149 \\
\hline 7 & Water Science and Technology (Q3) & IWA Publishing & 130 & $1.874 \%$ & 1,740 & 1.624 \\
\hline 8 & $\begin{array}{c}\text { Industrial Engineering Chemistry } \\
\text { Research (Q1) }\end{array}$ & $\begin{array}{c}\text { American Chemical } \\
\text { Society }\end{array}$ & 90 & $1.297 \%$ & 1,918 & 3.375 \\
\hline 9 & Chemical Engineering Journal (Q1) & Elsevier Science SA & 89 & $1.283 \%$ & 2,429 & 8.355 \\
\hline 10 & $\begin{array}{c}\text { Separation Science and Technology } \\
\text { (Q3) }\end{array}$ & $\begin{array}{c}\text { Taylor \& Francis INC } \\
\text { (n) }\end{array}$ & 72 & $1.038 \%$ & 796 & 1.354 \\
\hline
\end{tabular}




\subsection{Preferred Journal}

Table 1 shows the top 10 most productive journals in reverse osmosis topic. The top two journals were published by Elsevier. Elsevier published five journals in total as shown in the table. Moreover, there were also two journals published by the American Chemical Society. The remaining three journals have been published by Desalination Publication, IWA Publishing (International Water Associations), and Taylor \& Francis, Inc.

The top journals by Elsevier were Desalination and Journal of Membrane Science, where the recorded total publication was 1,249 and 714 , respectively, also covering $18.002 \%$ and $10.291 \%$ of the total of publication. The total citations for Desalination were 40,314, and Journal of Membrane Science recorded 36,696 citations. These journals were also two of the top five most productive journals, followed by Desalination and Water Treatment (695, 10.017\%), Separation and Purification Technology (200, 2.883\%), which was also published by Elsevier and Water Research journal (189, 2.724\%).

According to the journal impact factor trend 2018, the journal with the highest journal impact trend 2018 of 8.355 had belonged to the Chemical Engineering Journal by Elsevier Science SA. Although the journal recorded only 89 total publications and 2,429 total citations, and ranked 9th, nevertheless, the journal impact factor trend 2018 was the highest. There were six journals with a journal impact factor of 5 and above. Moreover, although ranked 3rd with 695 records of complete publication, Desalination, and Water Treatment journal had the lowest journal impact factor trend 2018, which was 1.234.

Journal impact factor indicates for each journal, the yearly average number of citations received by articles published in the last two years. It is also recurrently used as a representative for the relatable to each journal within its field. According to Penava and Dorotea (2015) [16], the impact factor approximately provides the prestige of a journal that has been published individually. Hence, the journal impact factor should not be regarded as the only factor. Besides, the authors should acknowledge whether the journals will offer the research to the right audience or not and contribute to the research field.

Table 2. The top 25 most productive countries and academic institutions in reverse osmosis publications.

\begin{tabular}{|c|c|c|c|c|c|}
\hline No & Countries & Records & Percentage & $\begin{array}{l}\text { The Most Productive Academic } \\
\text { Institutions }\end{array}$ & $\begin{array}{l}\text { Total Publication of a } \\
\text { Given Academic } \\
\text { Institution }\end{array}$ \\
\hline 1 & USA & 1,252 & $18.046 \%$ & Yale University & 74 \\
\hline 2 & $\begin{array}{l}\text { People's Republic of } \\
\text { China }\end{array}$ & 963 & $13.88 \%$ & Chinese Academy of Science & 112 \\
\hline 3 & South Korea & 543 & $7.826 \%$ & Korea University & 109 \\
\hline 4 & Australia & 450 & $6.486 \%$ & University of Technology Sydney & 85 \\
\hline 5 & Spain & 442 & $6.371 \%$ & University Politecnica De Valencia & 41 \\
\hline 6 & Singapore & 285 & $4.108 \%$ & National University of Singapore & 136 \\
\hline 7 & India & 263 & $3.791 \%$ & Indian Institute of Technology & 41 \\
\hline 8 & Germany & 261 & $3.762 \%$ & RWTH Aachen University & 35 \\
\hline 9 & Saudi Arabia & 261 & $3.762 \%$ & $\begin{array}{l}\text { King Abdullah University of Science } \\
\text { Technology }\end{array}$ & 70 \\
\hline 10 & England & 240 & $3.459 \%$ & University of Bradford & 47 \\
\hline 11 & France & 237 & $3.416 \%$ & Universite De Toulouse & 24 \\
\hline 12 & Italy & 234 & $3.373 \%$ & University of Calabria & 61 \\
\hline 13 & Canada & 220 & $3.171 \%$ & University of Alberta & 34 \\
\hline 14 & Japan & 202 & $2.912 \%$ & Hiroshima University & 25 \\
\hline 15 & Iran & 199 & $2.868 \%$ & Islamic Azad University & 28 \\
\hline 16 & Netherlands & 177 & $2.551 \%$ & Delft University of Technology & 64 \\
\hline 17 & Israel & 153 & $2.205 \%$ & Ben Gurion University & 59 \\
\hline 18 & Poland & 151 & $2.176 \%$ & Silesian University of Technology & 58 \\
\hline 19 & Turkey & 146 & $2.104 \%$ & Istanbul Technical University & 31 \\
\hline 20 & Brazil & 135 & $1.946 \%$ & Universidade Federal De Rio De Janeiro & 28 \\
\hline 21 & Malaysia & 115 & $1.658 \%$ & University Teknologi Malaysia & 40 \\
\hline 22 & Belgium & 98 & $1.424 \%$ & Katholieke Universiteit Leuven & 49 \\
\hline 23 & Greece & 95 & $1.380 \%$ & Aristotle University of Thessaloniki & 24 \\
\hline 24 & Taiwan & 95 & $1.380 \%$ & Chung Yuan Christian University & 22 \\
\hline 25 & South Africa & 89 & $1.293 \%$ & Tshwane University of Technology & 13 \\
\hline
\end{tabular}




\subsection{Leading Countries, Top Institutions, and Collaborations}

Table 2 shows the top 25 most productive countries in reverse osmosis research. The USA was recorded as the top productive country with 1,252 total publications (18.046\%). The most productive academic institution in the USA was Yale University, and it recorded 74 total publications of a given academic institution. The second most productive country was the People's Republic of China which recorded 963 total publications $(13.88 \%)$ and the most productive academic institution with 112 total publications was the Chinese Academy of Science. South Korea was ranked third. Its total publications were 543 (7.826\%), which was significantly lower than the people's Republic of China's, and the top academic institution in South Korea was Korea University with 109 total publications of a given academic institution.

Two universities that were among the best 100 universities based on the World Universities Ranking 2018 [17] were Yale University and Korea University, which were ranked 17 th and $83 \mathrm{rd}$, respectively. These two universities were in the top 3 of the most productive countries and academic institutions. This indicates that the reverse osmosis research area gained attention in the world's leading universities. Malaysia was ranked 21st with 115 total publications and the most productive academic institution in this field was University Teknologi Malaysia with 40 total publication.

Fig. 3 shows the frequency of countries per region. The thicker the line, the stronger the link between countries. Bibliographic coupling is like co-citation; it is a measure of similarity using citation analysis to determine the similarity between documents. The greater the number of references between the two publications, the greater the bibliographic coupling between them [18].

In this analysis, the total countries that were recorded were 110 in total. Out of the 110,40 countries produced at least 30 articles. The USA led the list with the highest number of total link strength of 807,767 , the highest number of documents, with 1,096 documents in total, and the highest number of total citations of 44,421. It was followed by the People's Republic of China (839 documents, 14,949 citations), South Korea (503 documents, 11,031 citations), Australia (404 documents, 12,033 citations) and others. Malaysia recorded 104 documents and 2,478 citations.

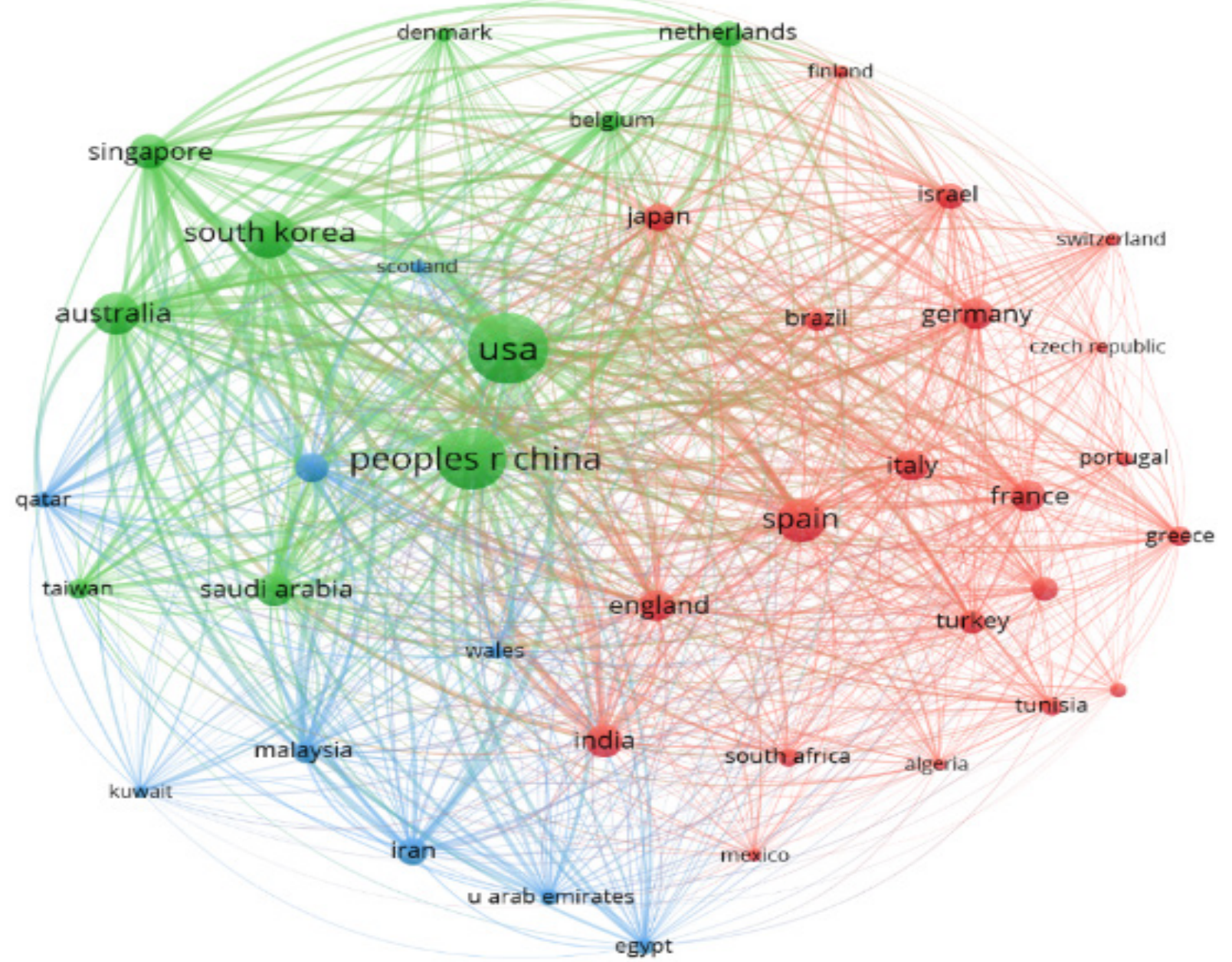

Figure 3. A screenshot of the bibliometric map created based on the bibliographic coupling of countries with network visualization mode. The minimum number of documents of a country is set to 30 . 
A Bibliometric Analysis of Reverse Osmosis: How Influential Can It Be?

Table 3. The list of research areas in reverse osmosis publications

\begin{tabular}{|c|c|c|}
\hline Research Areas & Records & Percentage \\
\hline Engineering & 5,127 & $73.887 \%$ \\
\hline Water Resources & 2,728 & $39.314 \%$ \\
\hline Environmental Sciences Ecology & 1,279 & $18.432 \%$ \\
\hline Polymer Science & 863 & $12.437 \%$ \\
\hline Chemistry & 649 & $9.353 \%$ \\
\hline Energy Fuels & 316 & $4.554 \%$ \\
\hline Material Science & 296 & $4.266 \%$ \\
\hline Science Technology Other Topics & 294 & $4.237 \%$ \\
\hline Food Science Technology & 249 & $3.558 \%$ \\
\hline Biotechnology Applied Microbiology & 148 & $2.133 \%$ \\
\hline Physics & 122 & $1.758 \%$ \\
\hline Agriculture & 106 & $1.528 \%$ \\
\hline Thermodynamics & 88 & $1.268 \%$ \\
\hline Marine Freshwater Biology & 72 & $1.038 \%$ \\
\hline Computer Science & 70 & $1.009 \%$ \\
\hline Biochemistry Molecular Biology & 58 & $0.836 \%$ \\
\hline Nuclear Science Technology & 45 & $0.649 \%$ \\
\hline Mechanics & 44 & $0.634 \%$ \\
\hline Public Environmental Occupational Health & 40 & $0.576 \%$ \\
\hline Geology & 37 & $0.533 \%$ \\
\hline Mining Mineral Processing & 34 & $0.490 \%$ \\
\hline Automation Control Systems & 25 & $0.360 \%$ \\
\hline Metallurgy Metallurgical Engineering & 23 & $0.331 \%$ \\
\hline Operations Research Management Science & 23 & $0.331 \%$ \\
\hline Meteorology Atmospheric Sciences & 22 & $0.317 \%$ \\
\hline Toxicology & 22 & $0.317 \%$ \\
\hline Electrochemistry & 21 & $0.303 \%$ \\
\hline Nutrition Dietetics & 17 & $0.245 \%$ \\
\hline Microbiology & 15 & $0.216 \%$ \\
\hline Pharmacology Pharmacy & 14 & $0.202 \%$ \\
\hline Urology Nephrology & 12 & $0.173 \%$ \\
\hline Geochemistry Geophysics & 11 & $0.159 \%$ \\
\hline Instruments Instrumentation & 11 & $0.159 \%$ \\
\hline Plant Sciences & 11 & $0.159 \%$ \\
\hline Oceanography & 10 & $0.144 \%$ \\
\hline Crystallography & 9 & $0.130 \%$ \\
\hline Construction Building Technology & 8 & $0.115 \%$ \\
\hline Mathematics & 8 & $0.115 \%$ \\
\hline Mineralogy & 8 & $0.115 \%$ \\
\hline Acoustics & 6 & $0.086 \%$ \\
\hline Biophysics & 6 & $0.086 \%$ \\
\hline
\end{tabular}




\subsection{Research Area}

Table 3 shows the overview of research areas in this study. Reverse osmosis topic mostly occurred in the engineering area with 5,127 total number of articles $(73.887 \%)$. The water resources area was ranked 2 nd with 2,728 total number of articles about reverse osmosis (39.314\%). In the 3rd rank was Environmental Sciences Ecology, which recorded 1,279 total number of articles $(18.432 \%)$. These top three research areas recorded more than a thousand articles about reverse osmosis. Also, these three research areas are related to each other; the application of scientific concepts to the design and construction of machines and structures is known as engineering and the reverse osmosis process is done by using a machine. RO is a water purification method that removes ions, unwanted molecules, and larger particles from drinking water using a partly permeable membrane, and it is connected to water supplies. Environmental Sciences Ecology will solve problems related to water pollution and reverse osmosis can help to treat water quality.

The other research areas are Polymer Science (863, 12.437\%), Chemistry (649, 9.353\%), Energy Fuels (316, 4.554\%), Material Science (296, 4.266\%), Science Technology other topics $(294,4.237 \%)$, Food Science Technology (249, 3.558\%), Biotechnology Applied Microbiology (148, 2.133\%), Physics (122, 1.758\%), and Agriculture (106, 1.528\%). In the mathematics area, there were only eight articles, $(0.115 \%)$.

\subsection{Leading Authors}

Table 4 shows the 15 most productive authors in reverse osmosis topic from eight different countries, which are South Korea (four authors), USA (one author), Singapore (two authors), Australia (two authors), Italy (one author), People's Republic China (three authors), England (one author) and Belgium (one author). The top author is Lee, Sangheon who is from South Korea with a total publication of $90(1.297 \%)$ and $24 \mathrm{~h}$-index. The second author is from the USA, Elimelech, Menachem, with 72 total publications $(1.038 \%)$ and an h-index of 49 is the highest h-index among all authors. Next, Chung, Tai-Shung from Singapore is ranked third with 62 total publications $(0.894 \%)$ and $24 \mathrm{~h}$-index. Following this, the top author is related to the leading countries which recorded the USA and South Korea as the most productive countries and author.

Fig. 4 shows the network of authors in reverse osmosis. The closer the link between authors, the stronger the relation between them. There are four different clusters represented by colours (red, blue, green, and yellow). The colour of an item is determined by the cluster to which the item belongs. The green cluster seems to cover research in reverse osmosis membrane and engineering. The red cluster seems relate to agriculture, and food science and technology. The blue cluster and yellow cluster seem to relate in water treatment and polymer science technology. Thus, the highest number of documents, citations and total link strength is under the green cluster, which is Elimelech, Menachem with the 91,867 , the highest total link strength.

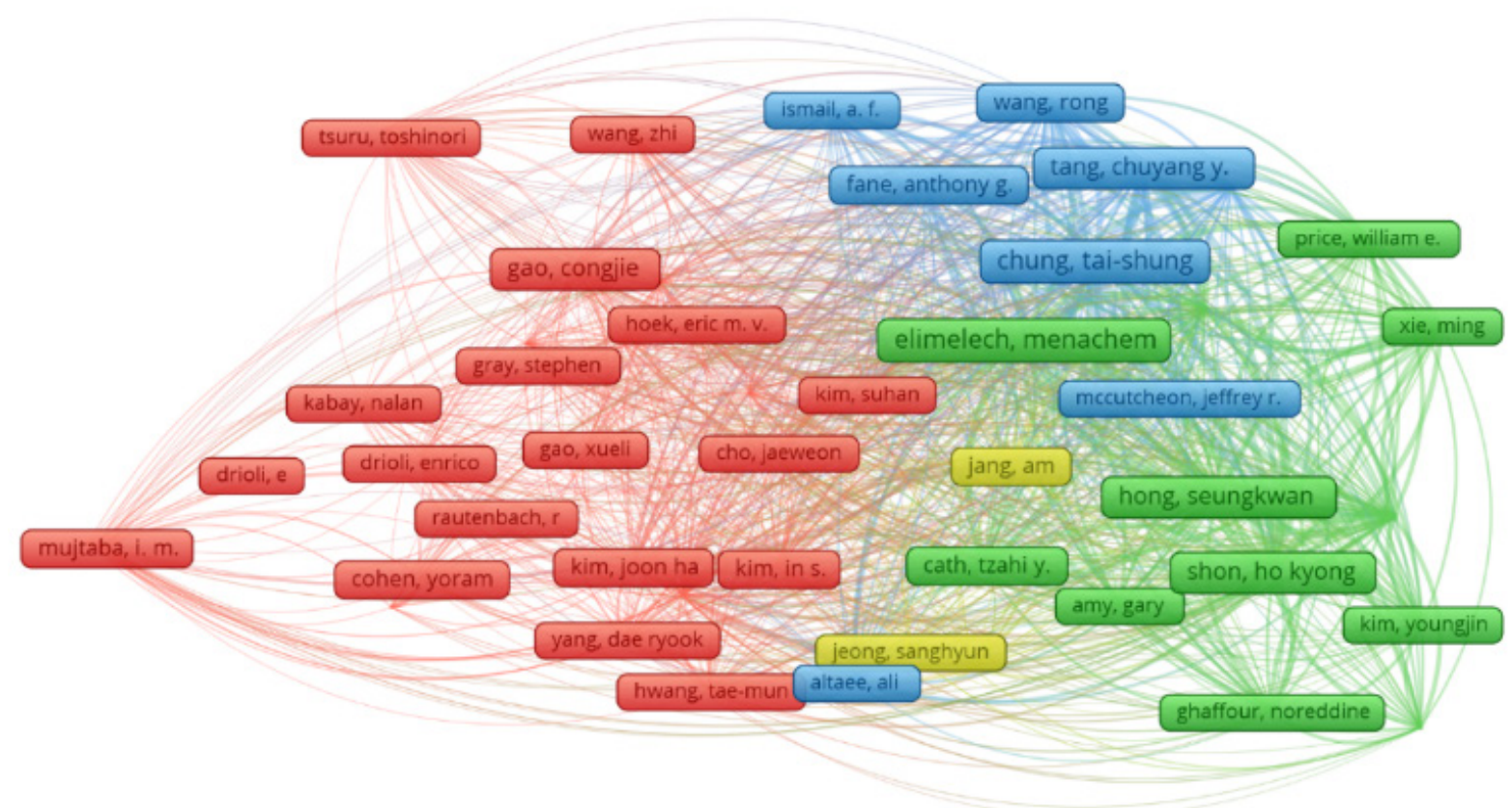

Figure 4. A screenshot of the bibliometric map created based on the bibliographic coupling of authors with network visualization mode. The minimum number of documents of a country is set to 30 . 
Table 4. The list of the most productive authors in reverse osmosis research area

\begin{tabular}{|c|c|c|c|c|c|}
\hline No & Authors & Total publications & Percentage & h-index & Country \\
\hline 1 & Lee, Sangheon & 90 & $1.297 \%$ & 24 & South Korea \\
\hline 2 & Elimelech, Menachem & 72 & $1.038 \%$ & 49 & USA \\
\hline 3 & Chung, Tai-Shung & 62 & $0.894 \%$ & 32 & Singapore \\
\hline 4 & Kim, Joon Ha & 61 & $0.879 \%$ & 18 & South Korea \\
\hline 5 & Shon, Ho Kyong & 60 & $0.865 \%$ & 20 & Australia \\
\hline 6 & Hong, Seungkwan & 58 & $0.836 \%$ & 25 & South Korea \\
\hline 7 & Drioli, Enrico & 55 & $0.793 \%$ & 25 & Italy \\
\hline 8 & Gao, Congjie & 53 & $0.764 \%$ & 19 & $\begin{array}{c}\text { People's Republic } \\
\text { of China }\end{array}$ \\
\hline 9 & Nghiem, Long Duc & 48 & $0.692 \%$ & 29 & Australia \\
\hline 10 & Fane, Anthony Gordon & 45 & $0.649 \%$ & 25 & Singapore \\
\hline 11 & Mujtaba, Iqbal Mohammed & 45 & $0.649 \%$ & 11 & England \\
\hline 12 & Wang, Jie & 42 & $0.605 \%$ & 12 & $\begin{array}{c}\text { People's Republic of } \\
\text { China }\end{array}$ \\
\hline 13 & Wang, Yan & 41 & $0.591 \%$ & 15 & $\begin{array}{c}\text { People's Republic of } \\
\text { China }\end{array}$ \\
\hline 14 & Kim, Seungju & 37 & $0.533 \%$ & 13 & South Korea \\
\hline 15 & Van Der Bruggen, Bart & 37 & $0.533 \%$ & 17 & Belgium \\
\hline
\end{tabular}

\subsection{Document Types}

Table 5 shows the document types, including retracted publication, related to reverse osmosis. The highest document type is article, with 6,451 records (92.967\%). It is followed distantly by proceeding papers $(1,378$, $19.859 \%)$, book chapters $(121,1.744 \%)$, early access $(11$, $0.159 \%)$, data paper $(3,0.043 \%)$, and retracted publication $(1,0.014 \%)$.

Table 5. The list of document types that have been used in reverse osmosis research area

\begin{tabular}{|c|c|c|}
\hline Document types & Records & Percentage \\
\hline Article & 6,451 & $92.967 \%$ \\
\hline Proceedings paper & 1,378 & $19.859 \%$ \\
\hline Book chapter & 121 & $1.744 \%$ \\
\hline Early access & 11 & $0.159 \%$ \\
\hline Data paper & 3 & $0.043 \%$ \\
\hline $\begin{array}{c}\text { Retracted } \\
\text { publication }\end{array}$ & 1 & $0.014 \%$ \\
\hline
\end{tabular}

\subsection{Languages}

In the field of reverse osmosis, there are 16 languages used for all the document types in Web of Science, and there is one unspecified language. The languages of the documents published were dominated by English, which is $98.155 \%$ (6,811 records) in total. The other languages that had been used are German, Polish, Chinese, Spanish, and Portuguese. Since the leading country for this research is the USA (Table 2), English is the most used language. Besides, most of the journals listed in Table 1 were published in English, so English was expected to have a higher percentage.

Table 6. The list of languages that have been used in reverse osmosis research area

\begin{tabular}{|c|c|c|c|}
\hline No & Languages & Records & Percentage \\
\hline 1 & English & 6,811 & $98.155 \%$ \\
\hline 2 & German & 26 & $0.375 \%$ \\
\hline 3 & Polish & 20 & $0.288 \%$ \\
\hline 4 & Chinese & 16 & $0.231 \%$ \\
\hline 5 & Spanish & 15 & $0.216 \%$ \\
\hline 6 & Portuguese & 11 & $0.159 \%$ \\
\hline 7 & Japanese & 9 & $0.130 \%$ \\
\hline 8 & French & 6 & $0.086 \%$ \\
\hline 9 & Korean & 5 & $0.072 \%$ \\
\hline 10 & Italian & 4 & $0.058 \%$ \\
\hline 11 & Russian & 4 & $0.058 \%$ \\
\hline 12 & Croatian & 3 & $0.043 \%$ \\
\hline 13 & Czech & 3 & $0.043 \%$ \\
\hline 14 & Turkish & 3 & $0.043 \%$ \\
\hline 15 & Romanian & 1 & $0.014 \%$ \\
\hline 16 & Ukrainian & 1 & $0.014 \%$ \\
\hline 17 & Unspecified & 1 & $0.014 \%$ \\
\hline
\end{tabular}

\section{Conclusion}

This paper evaluated a summary of the developments in reverse osmosis process research based on 6,938 
publications from the WOS database. Based on the author keywords co-occurrence analysis, the general terms were usually found in "desalination", "nanofiltration", "forward osmosis" and "ultrafiltration". We have discovered countries and academic institutions, for instance, USA, which have many publications and strong international collaborations. Furthermore, as shown in the VOSviewer mapping, the USA had the highest number of total link strength $(807,767)$ and the highest number of documents $(1,096)$. The research areas showed that Engineering was mostly found in reverse osmosis research. In future research, related contents could be more extensive and should be more specific to different research subjects. Hence, to choose an adequate research method, the research front still needs to work harder to explore more things about the reverse osmosis process and in-depth expansion.

\section{Acknowledgements}

This research was funded by a grant from Ministry of Higher Education of Malaysia (FGRS Grant RDU 160116) (Ref: FGRS/1/2016/STG06/UMP/02/3).

\section{REFERENCES}

[1] Greenlee, L. F., Lawler, D. F., Freeman, B. D., Marrot, B., \& Moulin, P. (2009). Reverse Osmosis Desalination: Water Sources, Technology, And Today's Challenges. Water Research, 43(9), 2317-2348.

[2] Petersen, R. J. (1993). Composite Reverse Osmosis and Nanofiltration Membranes. Journal of Membrane Science, 83(1), 81-150.

[3] Gambier, A., \& Badreddin, E. (2009). Control of Small Reverse Osmosis Desalination Plants with Feed Water Bypass. IEEE Control Applications, (CCA) \& Intelligent Control, (ISIC), 800-805.

[4] Tanaka, H., \& Ho, Y. S. (2011). Global Trends and Performances of Desalination Research. Desalination and Water Treatment, 25(1-3), 1-12.

[5] Braun, T., Schubert, A. P., \& Kostoff, R. N. (2000). Growth and Trends of Fullerene Research as Reflected in Its Journal Literature. Chemical Reviews, 100(1), 23-38.
[6] Schubert, A., Glanzel, W., \& Braun, T. (1989). Scientometric Datafiles: A Comprehensive Set of Indicators On 2649 Journals And 96 Countries in All Major Science Fields and Subfields World Flash on Basic Research, 1981-1985.

[7] Bayer, A. E., \& Folger, J. (1966). One Correlates of a Citation Measure of Productivity in Science. Sociology of Education, 381-390.

[8] Li, D., \& Wang, H. (2010). Recent Developments in Reverse Osmosis Desalination Membranes. Journal of Materials Chemistry, 20(22), 4551-4566.

[9] Khudzari, J. M., Kurian, J., Tartakovsky, B., \& Raghavan, G. V. (2018). Bibliometric Analysis of Global Research Trends on Microbial Fuel Cells Using Scopus Database. Biochemical Engineering Journal, 136, 51-60.

[10] Archambault, É., Campbell, D., Gingras, Y., \& Larivière, V. (2009). Comparing Bibliometric Statistics Obtained from The Web of Science and Scopus. Journal of The American Society for Information Science and Technology, 60(7), $1320-1326$

[11] Ding, Y., Chowdhury, G. G., \& Foo, S. (2001). Bibliometric Cartography of Information Retrieval Research by Using Co-Word Analysis. Information Processing \& Management, 37(6), 817-842.

[12]Dai, Y., Song, Y., Gao, H., Wang, S., \& Yuan, Y. (2015). Bibliometric Analysis of Research Progress in Membrane Water Treatment Technology From 1985 To 2013. Scientometrics, 105(1), 577-591.

[13] Wen, H., \& Huang, Y. (2012). Trends and Performance of Oxidative Stress Research From 1991 To 2010. Scientometrics, 91(1), 51-63.

[14] Ahmad, A. L., Chong, M. F., Bhatia, S., \& Ismail, S. (2006). Drinking Water Reclamation from Palm Oil Mill Effluent (POME) Using Membrane Technology. Desalination, 191(1-3), 35-44

[15] Yang, L., Guo, H., Chen, H., He, L., \& Sun, T. (2018). A Bibliometric Analysis of Desalination Research During 1997-2012. Water Conservation \& Management (WCM), $2(1), 18-23$

[16] Iva Penava \& Dorotea Kušt(nd) (2015). Advantages and disadvantages of journal impact factor. University of Zagreb Faculty of Law Department of Social Work.

[17] QS Top Universities, "QS World University Rankings 2018" Https://www.topuniversities.com/university-rankings/world -university-rankings/2018 (accessed Jan. 22, 2019).

[18] Van Eck, N. J., \& Waltman, L. (2014). Visualizing Bibliometric Networks. In Measuring Scholarly Impact, 285-320. 